\title{
Proliferation of Bifidobacteria by Oligosaccharides and Their Useful Effect on Human Health
}

\author{
Hidemasa Hidaka, Yasuhito TAshiro and Toshiaki Eida \\ Bio Science Laboratories, Meiji Seika Kaisha, Ltd., Chiyoda, Sakado, Saitama 350-02
}

(Received for publication, August 20, 1990)

\begin{abstract}
Studies of oligosaccharides have recently become common, especially in Japan. This has been because of findings of marked biofunctions and usefulness of fructooligosaccharides (FOS) for human health due to their effect of improving the intestinal microflora. In this paper, we demonstrate several useful characteristics of FOS such as cholesterol reduction, suppression of putrefaction, normalization of microbial disorders of the colon and alleviation of constipation in clinical studies. It seems that the usefulness of FOS is related to the proliferation of bifidobacteria and other saccharolytic intestinal bacteria and also short chain fatty acids produced by these organisms.
\end{abstract}

Key words: fructooligosaccharide, non-digestible carbohydrate, proliferation of Bifidobacterium, cholesterol reduction, improvement of constipation

In the last decade, the number of people suffering from circulatory organ diseases such as obesity, diabetes, ischemic heart disease and colon cancer has been gradually increasing particularly in the industrialized countries thanks to the abundant and rich food supply. Dietary fiber is one nutrient which is thought to prevent these diseases. According to recent studies (1), people who eat a high-fat and low-fiber diet have a smaller number of bifidobacteria in their intestines. Perhaps the beneficial effect of dietary fiber on some diseases is owing to proliferation of bifidobacteria and subsequent improvement in the intestinal microflora.

Fructooligosaccharides (FOS) consist of 1-kestose $\left(\mathrm{GF}_{2}\right)$, nystose $\left(\mathrm{GF}_{3}\right)$ and $1^{F_{-}} \beta$-fructofuranosyl nystose $\left(\mathrm{GF}_{4}\right)$ and can be manufactured from sucrose using a fungal $\beta$-fructofuranosides $(6)$. Their structures and composition are illustrated in Fig. 1. FOS occur naturally in many kinds of plants such as onions, asparagus root, bananas and wheat (13). The nondigestibility of FOS has been confirmed by in vitro digestion with mammalian hydrolyzing enzymes (15) and a clinical study (17) showing that there is no formation of glucose and fructose. Furthermore, FOS are fermented and metabolized to short chain fatty acids (SCFA) and $\mathrm{CO}_{2}$ by the intestinal microflora in rat (14) and in human (7). These data indicate that FOS are in non-digestible, fermentable and dietary fiber-like saccharides (Table 1). 


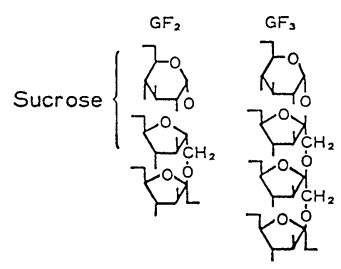

$30 \% \quad 57 \%$

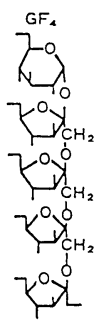

$13 \%$

Fig. 1. Chemical structures and composition of FOS.

Table 1. Classification of saccharides by digestibility

\begin{tabular}{|c|c|c|c|}
\hline Nutrient & Small intestine & Large intestine & Example \\
\hline \multirow{3}{*}{ Saccharides } & digestible & (fermentable) & $\begin{array}{l}\text { glucose, fructose, } \\
\text { maltose, lactose, } \\
\text { starch, etc. }\end{array}$ \\
\hline & \multirow[t]{2}{*}{ non-digestible } & fermentable & $\begin{array}{l}\text { dietary fibers } \\
\text { (pectin, plant gums, etc.) } \\
\text { raffinose, stachyose, } \\
\text { fructooligosaccharides }\end{array}$ \\
\hline & & $\begin{array}{l}\text { non (or less)- } \\
\text { fermentable }\end{array}$ & $\begin{array}{l}\text { dietary fibers } \\
\text { (agar, cellulose, etc.) }\end{array}$ \\
\hline
\end{tabular}

The utilization of FOS by human intestinal bacteria is shown in Table 2. FOS can be utilized by the predominant Bifidobacterium sp., species in Bacteroides fragilis group and some other bacteria like other nondigestible saccharides. However, it cannot be utilized by undesirable putrefactive bacteria such as Clostridium perfringens, Clostridium difficile or Escherichia coli. The effect of FOS ingestion on the human intestinal microflora was also studied (13), and proliferation of bifidobacteria by FOS was recognized, as shown in Fig. 2.

In this paper, by means of clinical studies, we present FOS as a bifidogenic factor which exerts useful physiological effects on human health.

\section{MATERIALS AND METHODS}

After informed consent was obtained from human subjects, we performed the following clinical studies.

Administration of FOS to hyperlipidemic patients. Forty-six hyperlipidemic outpatients (20 men, 26 women) participated in a study of the effect of FOS on serum lipids. The subjects were randomly assigned to a FOS administration group or a sucrose (placebo) administration group, as shown in Fig. 3. Prepared as 5 kinds of confectioneries, FOS ( $8 \mathrm{~g} /$ day) were administrated to the subjects for a period of 5 weeks. In the sucrose group, FOS were replaced by the same amount of sucrose. 
Table 2. Utilization of several sugars by some human intestinal bacteria ${ }^{a}$ )

\begin{tabular}{|c|c|c|c|c|c|c|c|}
\hline \multirow[t]{2}{*}{ Bacterial species } & \multicolumn{2}{|c|}{$\begin{array}{c}\text { Isolation from } \\
\text { human intestine }\end{array}$} & \multirow{2}{*}{$\begin{array}{l}\text { No. of } \\
\text { strains }\end{array}$} & \multirow[t]{2}{*}{ Glucose } & \multirow[t]{2}{*}{ Lactulose } & \multirow[t]{2}{*}{ Raffinose } & \multirow{2}{*}{$\begin{array}{l}\text { Fructooligo- } \\
\text { saccharides }\end{array}$} \\
\hline & $\%$ positive & Mean & & & & & \\
\hline Bifidobacterium adolescentis & 54.6 & 10.0 & 4 & $H$ & H & $H$ & H \\
\hline longum & 21.3 & 9.9 & 3 & H & H & H & H \\
\hline breve & 9.9 & 9.2 & 3 & $H$ & H & H & + \\
\hline infantis & 24.8 & 9.8 & 2 & H & H & H & H \\
\hline bifidum & 5.0 & 10.2 & 2 & H & H & - & - \\
\hline Lactobacillus acidophilus & 44.7 & 9.2 & 3 & H & H & $-\#$ & - \\
\hline fermentum & 38.3 & 8.4 & 4 & $H$ & $H^{-}$ & V & - \\
\hline plantarum & 29.8 & 8.8 & 1 & H & H & - & + \\
\hline Eubacterium aerofaciens & 48.9 & 9.7 & 1 & H & H & - & + \\
\hline lentum & 42.6 & 9.3 & 1 & - & - & - & - \\
\hline Bacteroides fragilis & 46.1 & 10.4 & 4 & H & H & H & H \\
\hline thetaiotaomicron & 86.5 & 10.7 & 3 & H & H & H & H \\
\hline vulgatus & 69.5 & 10.6 & 2 & $H$ & H & H & H \\
\hline Escherichia coli & 92.9 & 8.6 & 2 & H & H & $\mathrm{V}$ & - \\
\hline Klebsiella pneumoniae & 19.9 & 7.7 & 1 & H & - & H & $H$ \\
\hline Enterococcus faecalis & 80.1 & 7.5 & 1 & H & + & - & + \\
\hline faecium & 30.5 & 7.9 & 1 & $H$ & H & - & + \\
\hline Streptococcus intermedius & 27.7 & 10.2 & 2 & H & $H$ & - & $H$ \\
\hline Peptostreptococcus prevotii & 16.3 & 10.0 & 1 & H & - & $H$ & - \\
\hline Clostridium perfringens & 41.1 & 7.1 & 4 & H & H & + & - \\
\hline difficile & 0.7 & 4.8 & 2 & H & - & - & - \\
\hline paraputrificum & 9.9 & 8.5 & 2 & H & + & - & - \\
\hline clostridiiforme & 8.5 & 9.0 & 2 & H & $H$ & H & + \\
\hline ramosum & 53.2 & 9.1 & 2 & $H$ & H & + & + \\
\hline Veillonella dispar & 34.0 & 7.9 & 2 & - & - & - & - \\
\hline Megasphaera elsdenii & 5.0 & 9.4 & 1 & - & - & - & - \\
\hline
\end{tabular}

a) Judgement of bacterial growth: H, same level of growth compared to glucose; +, weaker growth compared to glucose; -, no growth; $\mathrm{V}$, variable (strains may be either + or $-)$; superscripts indicate the results of occasional strains in the species.

b) Finegold, S.M. et al (1983) (3).

After fasting, the serum total cholesterol, triglycerides, HDL-cholesterol, free fatty acids, blood sugar, uric acid, blood pressure and body weight were measured before and after the study.

Administration of FOS to hypercholesterolemic subjects. Eight hypercholesterolemic subjects ( 7 men, 1 woman) with type IIa hyperlipoproteinemia were recruited for this study. Their ages ranged from 37 to 67 years old, and their lipid profiles before the study are shown in Table 4 . FOS $(8 \mathrm{~g} /$ day) were ingested as a packed syrup in the manner decided by each subject without altering their eating habits for a period of one month. Serum total cholesterol, HDL-cholesterol, triglycerides and apolipoproteins were measured before and after the administration. Serum apolipoprotein A-I, B and E were determined by single radial immunodiffusion (SRID) method (12) using SRID plates supplied by Daiichi Pure Chemicals Co., 


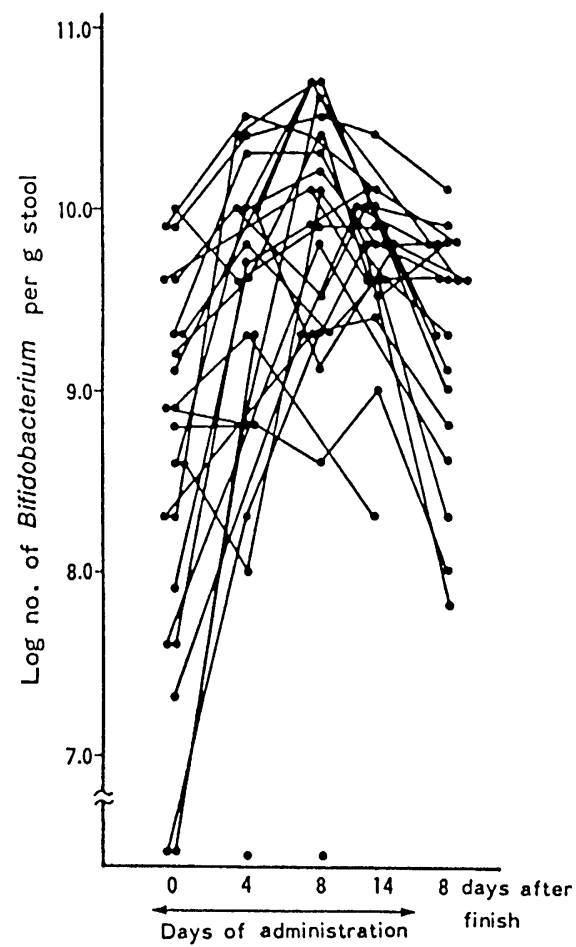

Fig. 2. Changes in fecal bifidobacteria by the administration of FOS. FOS ( $8 \mathrm{~g} /$ day $)$ were administered to aged subjects.

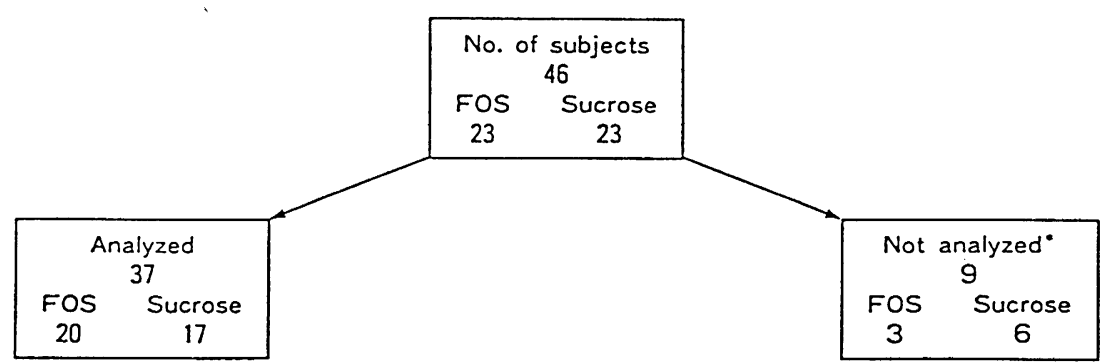

* Reason:

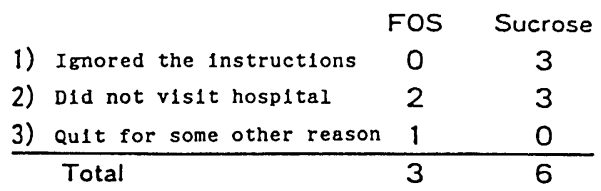

Fig. 3. Handling of subjects who participated in the study of the effect of FOS administration on hyperlipidemia (Blind test). 


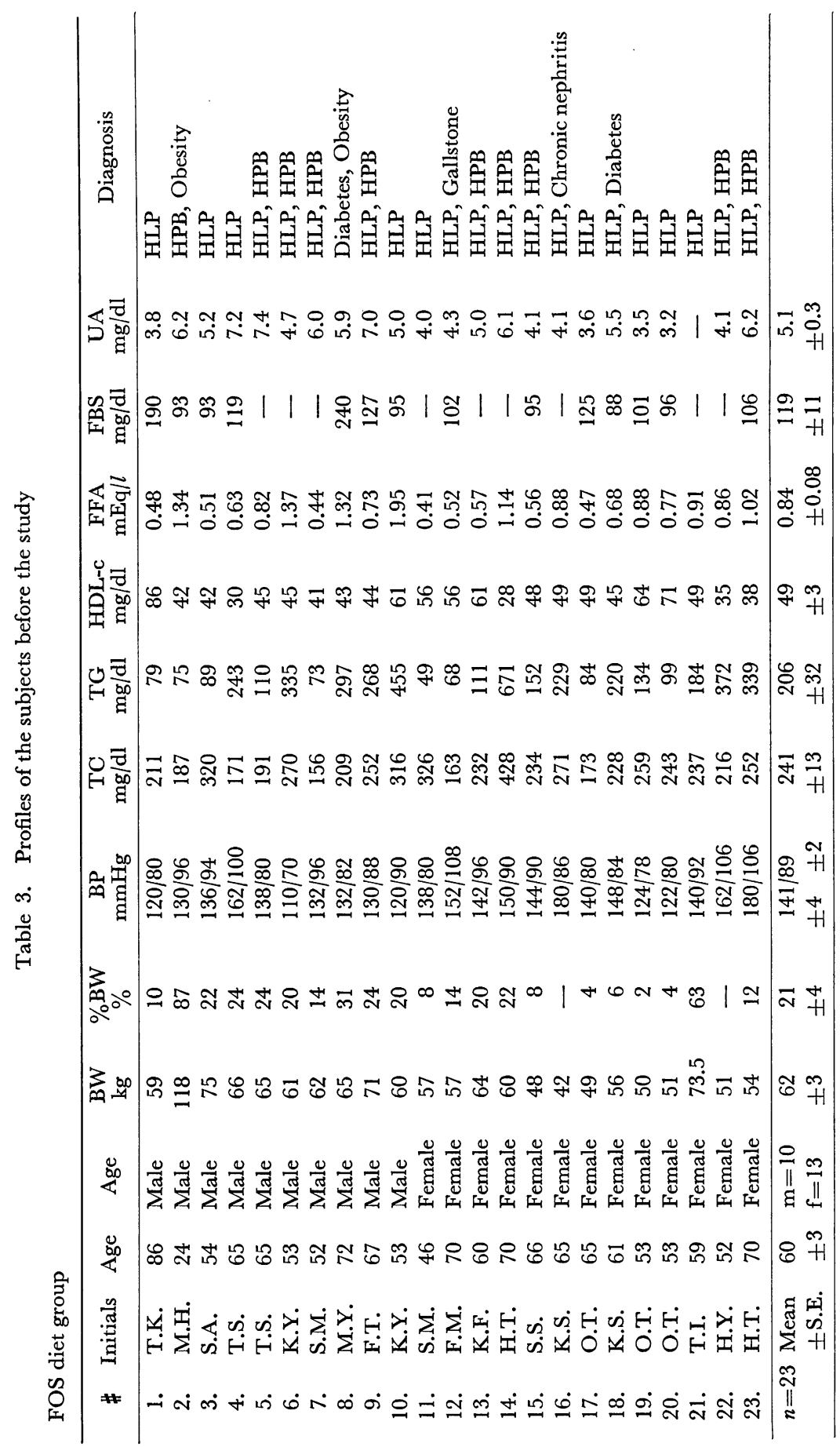




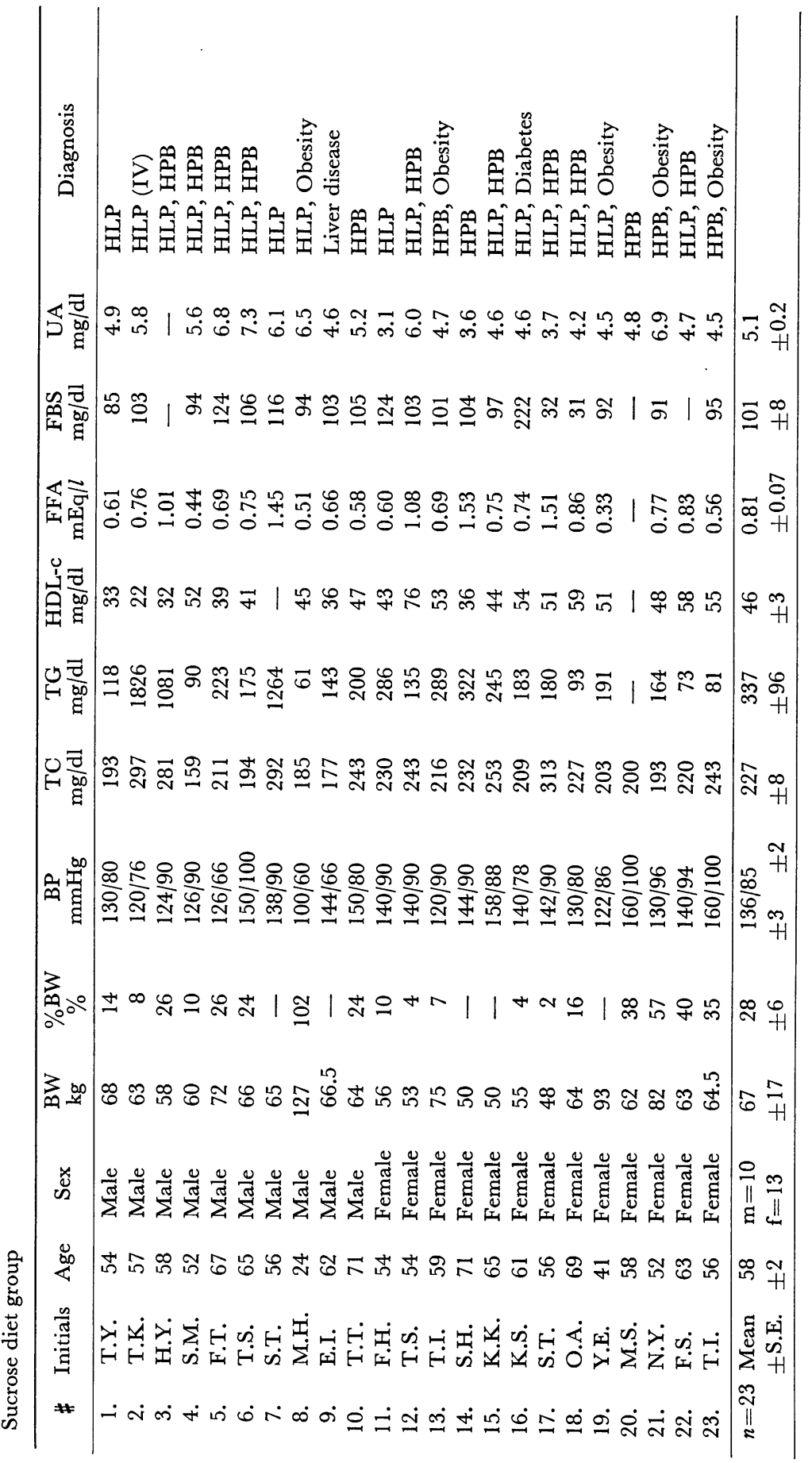


Table 4. Lipid profiles of hyperlipidemic subjects before FOS administration

\begin{tabular}{lccccccc}
\hline Subject & $\begin{array}{c}\text { TC } \\
(\mathrm{mg} / \mathrm{dl})\end{array}$ & $\begin{array}{c}\text { HDL-C } \\
(\mathrm{mg} / \mathrm{dl})\end{array}$ & $\begin{array}{c}\text { TG } \\
(\mathrm{mg} / \mathrm{dl})\end{array}$ & $\begin{array}{c}\text { Apo A-I } \\
(\mathrm{mg} / \mathrm{dl})\end{array}$ & $\begin{array}{c}\text { Apo B } \\
(\mathrm{mg} / \mathrm{dl})\end{array}$ & $\begin{array}{c}\text { Apo E } \\
(\mathrm{mg} / \mathrm{dl})\end{array}$ & Type \\
\hline S.N. & 287 & 68.9 & 55 & 136 & 138 & 2.5 & IIa \\
Y.S. & 263 & 43.4 & 144 & 114 & 151 & 3.4 & IIa \\
H.N. & 277 & 49.7 & 67 & 130 & 145 & 2.8 & IIa \\
K.I. & 285 & 59.4 & 177 & 145 & 145 & 4.6 & IIa \\
T.S. & 293 & 60.9 & 171 & 150 & 180 & 4.9 & IIa \\
Y.I. & 289 & 76.4 & 96 & 150 & 151 & 3.4 & IIa \\
N.N. & 258 & 50.6 & 98 & 123 & 173 & 2.8 & IIa \\
Y.F. & 280 & 50.0 & 141 & 156 & 158 & 3.3 & IIa \\
\hline
\end{tabular}

Ltd. The intestinal microflora, SCFA and putrefactive substances were also analyzed before and after the study.

Long-term administration of FOS. Ten chronic renal failure patients ( 6 men 4 women) and six healthy persons ( 3 men, 3 women) with a mean age of 45.0 years and 49.5 years, respectively, participated in this study. FOS (8 g/day) were administered to the subjects, and the intestinal microflora were investigated over a period of one year.

Administration of FOS to constipated people. Fifteen functionally constipated subjects ( 5 men, 10 women) ranging from 20 to 82 years old took part in this study of the effect of FOS ingestion on constipation. The dose level of FOS was chosen between $5 \mathrm{~g}$ and $20 \mathrm{~g}$ depending on the condition of the subject. In 3 subjects who had taken a laxative before the study, continued intake of the agent was allowed during the study. The daily times of defecation by each subject were recorded on a questionnaire every 14 days, and the average interval between evacuations was calculated.

Investigation of the intestinal microflora and determination of fecal substances. Investigation of the intestinal microflora was performed as described previously (5). Fecal SCFA and putrefactive substances were measured by gas chromatography. The extraction procedure from the stool and the analytical conditions of those substances were as described previously (5).

\section{RESULTS}

\section{Effect of FOS on Hyperlipidemia}

Nine subjects failed to complete the protocol, as shown in Fig. 3. The results are therefore presented for 37 subjects. Figure 4 depicts the changes in the serum total cholesterol, triglycerides, blood pressure and fasting blood sugar for the FOS and sucrose diet groups. The total cholesterol and diastolic blood pressure were significantly reduced on the FOS diet in comparison with the sucrose diet. There was a tendency for the FOS diet to reduce the serum triglycerides and blood sugar, as shown in Fig. 4, and free fatty acids (4). No significant differences were observed in HDL-cholesterol, body weight and uric acids between the two diet groups in this study. 


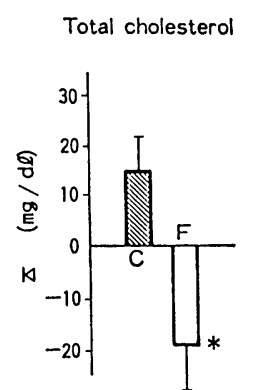

Blood pressure

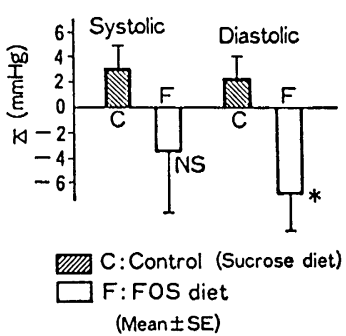

Triglycerides

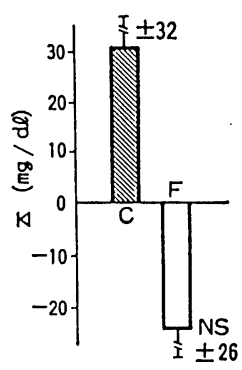

Fasting blood sugar

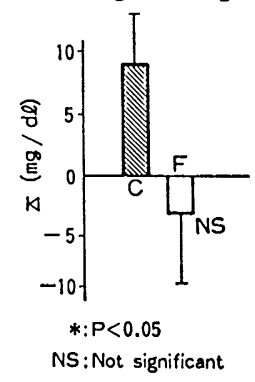

Fig. 4. Effect of FOS administration on serum total cholesterol, triglycerides, blood pressure and fasting blood sugar.

Table 5. Effects of FOS on serum lipids

\begin{tabular}{lcc}
\hline Serum component & Initial & After FOS \\
\hline Total cholesterol & $277.6 \pm 15.1 a)$ & $260.0 \pm 29.0$ \\
HDL-cholesterol & $57.3 \pm 11.5$ & $57.7 \pm 13.4$ \\
Triglycerides & $119.8 \pm 41.8$ & $119.6 \pm 51.8$ \\
Apoprotein A-I & $138.3 \pm 14.3$ & $145.2 \pm 22.1$ \\
Apoprotein B & $160.3 \pm 20.7$ & $152.2 \pm 24.0$ \\
Apoprotein E & $3.6 \pm 1.0$ & $\left.4.8 \pm 1.6^{b}\right)$ \\
\hline
\end{tabular}

a) Data expressed as mean $\pm \mathrm{SD}$ of $\mathrm{mg} / \mathrm{dl}$ of serum.

b) Significantly different from initial value at $P<0.05$ (paired $t$-test).

\section{Effect of FOS on Hypercholesterolemia}

Table 5 compares the serum components initially and after one month of FOS intake. Total cholesterol and apoprotein B were decreased, although this reduction was not significant, while HDL-cholesterol and triglycerides remained unchanged. Apoprotein E was significantly increased after one month of FOS ingestion.

In this study, total cholesterol was reduced by more than $10 \%$ in 4 subjects. We regarded such cases as effective and then analyzed their data separately from those for the ineffective cases (Table 6). The initial apoprotein B level was signif- 
Table 6. Comparison of serum lipids between effective and ineffective cases

\begin{tabular}{clcc}
\hline \multicolumn{2}{c}{ Serum component } & Effective cases & Ineffective cases \\
\hline \multirow{2}{*}{ Total cholesterol } & (Initial) & $278.0 \pm 10.9^{a}$ & $280.0 \pm 15.6$ \\
& (After FOS) & $246.3 \pm 12.1$ & $279.3 \pm 12.6^{* *}$ \\
HDL-cholesterol & (Initial) & $55.4 \pm 11.2$ & $59.5 \pm 12.3$ \\
& (After FOS) & $66.2 \pm 12.3$ & $56.2 \pm 11.8$ \\
Apoprotein A-I & (Initial) & $131.3 \pm 13.0$ & $144.8 \pm 14.8$ \\
& (After FOS) & $137.5 \pm 9.6$ & $155.0 \pm 21.1$ \\
Apoprotein B & (Initial) & $144.8 \pm 5.3$ & $165.5 \pm 13.3^{*}$ \\
\multirow{2}{*}{ Apoprotein E } & (After FOS) & $139.0 \pm 10.7$ & $165.8 \pm 28.5$ \\
& (Initial) & $3.3 \pm 0.9$ & $3.6 \pm 0.9$ \\
& (After FOS) & $4.3 \pm 0.4$ & $5.2 \pm 1.9$ \\
\hline
\end{tabular}

a) Data expressed as mean $\pm \mathrm{SD}$ of $\mathrm{mg} / \mathrm{dl}$ of serum.

Significant difference between effective and ineffective cases : *, at $P<0.05 ; * *$, at $P<0.01$ (paired $t$-test).

Table 7. Comparison of predominant intestinal microflora between effective and ineffective cases

\begin{tabular}{|c|c|c|c|c|c|}
\hline \multicolumn{2}{|c|}{ Bacterial group } & \multicolumn{2}{|c|}{ Effective case $^{a)}$} & \multicolumn{2}{|c|}{ Ineffective case ${ }^{a}$ ) } \\
\hline & & \multirow{2}{*}{$\begin{array}{r}\text { Counts }^{b)} \\
9.8 \pm 0.7\end{array}$} & \multirow{2}{*}{$\frac{\% \text { of flora }}{c)}$} & \multirow{2}{*}{$\frac{\text { Counts }}{10.2 \pm 0.6}$} & \multirow{2}{*}{$\frac{\% \text { of flora }}{-}$} \\
\hline Total counts & (Initial) & & & & \\
\hline & (After FOS) & $9.9 \pm 0.5$ & - & $10.1 \pm 0.4$ & - \\
\hline \multirow{2}{*}{ Bifidobacterium } & (Initial) & $8.8 \pm 1.6$ & 9.8 & $9.1 \pm 0.3$ & 7.9 \\
\hline & (After FOS) & $9.6 \pm 0.6$ & 50.1 & $9.4 \pm 0.5$ & 16.6 \\
\hline \multirow[t]{2}{*}{ Bacteroidaceae } & (Initial) & $9.6 \pm 0.6$ & 56.2 & $9.9 \pm 0.6$ & 47.9 \\
\hline & (After FOS) & $9.1 \pm 0.7$ & 16.6 & $9.7 \pm 0.9$ & 29.5 \\
\hline \multirow[t]{2}{*}{ Eubacterium } & (Initial) & $9.0 \pm 0.7$ & 14.8 & $9.7 \pm 0.9$ & 30.9 \\
\hline & (After FOS) & $9.3 \pm 0.4$ & 26.3 & $8.8 \pm 1.0$ & 3.6 \\
\hline \multirow[t]{2}{*}{ Enterobacteriaceae } & (Initial) & $6.6 \pm 0.5$ & $\mathrm{t}^{(\bar{d})}$ & $6.9 \pm 0.9$ & $\mathbf{t}$ \\
\hline & (After FOS) & $6.1 \pm 0.7$ & $\mathrm{t}$ & $6.9 \pm 0.2$ & $\mathrm{t}$ \\
\hline \multirow[t]{2}{*}{ Streptococcus } & (Initial) & $5.6 \pm 1.3$ & $\mathrm{t}$ & $6.8 \pm 0.7$ & $\mathrm{t}$ \\
\hline & (After FOS) & $6.5 \pm 1.4$ & $\mathrm{t}$ & $6.1 \pm 0.4$ & $\mathrm{t}$ \\
\hline \multirow[t]{2}{*}{ Lactobacillus } & (Initial) & $5.5 \pm 0.0$ & $t$ & $5.6 \pm 1.7$ & $\mathbf{t}$ \\
\hline & (After FOS) & $5.3 \pm 1.3$ & $\mathbf{t}$ & $4.6 \pm 2.9$ & $\mathrm{t}$ \\
\hline
\end{tabular}

a) No. of subjects: $n=3$.

b) Bacterial counts expressed as mean $\pm \mathrm{SD}$ of $\log _{10}$ per gram of wet stool.

c) $\%$ of flora expressed as mean counts of the organism/mean total counts $\times 100$.

d) Less than $0.1 \%$.

icantly low in the effective cases, while there were no differences in the initial total cholesterol, HDL-cholesterol or other lipoprotein levels.

We analyzed the intestinal microflora, SCFA and the putrefactive substances in 3 effective cases and 3 ineffective cases. Table 7 shows the changes in the predominant intestinal microflora in the effective and ineffective cases. There were no significant differences in the changes in the number of intestinal bacteria between the two groups. In the effective cases, Bifidobacterium increased by 5 times, i.e., from 
Table 8. Occurrence of SCFA and putrefactive substances between effective and ineffective cases

\begin{tabular}{|c|c|c|c|}
\hline Compound & & Effective $\operatorname{cases}^{a}$ ) & Ineffective cases $^{a}$ ) \\
\hline \multirow[t]{2}{*}{ Acetic acid } & (Initial) & $14.6 \pm 10.2^{b)}$ & $42.6 \pm 32.8$ \\
\hline & (After FOS) & $29.4 \pm 20.1$ & $26.4 \pm 15.5$ \\
\hline \multirow[t]{2}{*}{ Propionic acid } & (Initial) & $4.9 \pm 3.5$ & $10.1 \pm 2.7$ \\
\hline & (After FOS) & $6.1 \pm 4.1$ & $6.4 \pm 3.3$ \\
\hline \multirow[t]{2}{*}{ Butyric acid } & (Initial) & $5.3 \pm 5.7$ & $17.4 \pm 25.2$ \\
\hline & (After FOS) & $7.6 \pm 6.0$ & $6.9 \pm 6.9$ \\
\hline \multirow[t]{2}{*}{ Valeric acid } & (Initial) & $0.46 \pm 0.03$ & $1.98 \pm 0.39$ \\
\hline & (After FOS) & $0.80 \pm 0.60$ & $0.47 \pm 0.35$ \\
\hline \multirow[t]{2}{*}{ Total straight-chain SCFA } & (Initial) & $25.3 \pm 19.1$ & $72.2 \pm 60.4$ \\
\hline & (After FOS) & $43.9 \pm 30.7$ & $40.3 \pm 25.4$ \\
\hline \multirow[t]{2}{*}{ Isobutyric acid } & (Initial) & $0.79 \pm 0.59$ & $1.20 \pm 0.07$ \\
\hline & (After FOS) & $0.34 \pm 0.12$ & $0.41 \pm 0.06$ \\
\hline \multirow[t]{2}{*}{ Isovaleric acid } & (Initial) & $0.76 \pm 0.18$ & $2.20 \pm 0.69$ \\
\hline & (After FOS) & $0.67 \pm 0.21$ & $1.20 \pm 0.53$ \\
\hline \multirow[t]{2}{*}{ Total branched-chain SCFA } & (Initial) & $1.55 \pm 0.41$ & $3.40 \pm 0.76$ \\
\hline & (After FOS) & $1.01 \pm 0.32$ & $1.61 \pm 0.58$ \\
\hline \multirow[t]{2}{*}{ Indole } & (Initial) & $0.128 \pm 0.116$ & $0.075 \pm 0.067$ \\
\hline & (After FOS) & $0.042 \pm 0.013$ & $0.055 \pm 0.008$ \\
\hline \multirow[t]{2}{*}{ Skatole } & (Initial) & $0.037 \pm 0.016$ & $0.031 \pm 0.006$ \\
\hline & (After FOS) & $0.008 \pm 0.007$ & $0.021 \pm 0.019$ \\
\hline \multirow[t]{2}{*}{$p$-Cresol } & (Initial) & $0.234 \pm 0.251$ & $0.194 \pm 0.214$ \\
\hline & (After FOS) & $0.059 \pm 0.069$ & $0.165 \pm 0.103$ \\
\hline \multirow[t]{2}{*}{ Phenol } & (Initial) & $0.009 \pm 0.016$ & $0.046 \pm 0.080$ \\
\hline & (After FOS) & $\mathrm{ND}^{c)}$ & ND \\
\hline \multirow[t]{2}{*}{ Total putrefactive substances } & (Initial) & $0.408 \pm 0.360$ & $0.346 \pm 0.162$ \\
\hline & (After FOS) & $0.108 \pm 0.084$ & $0.242 \pm 0.119$ \\
\hline
\end{tabular}

a) No. of subjects: $n=3$.

b) Data expressed as mean $\pm \mathrm{SD}$ (mg per gram of dry stool).

c) Not detected (limit: $2 \mu \mathrm{g} / \mathrm{g}$ ).

$9.8 \%$ to $50.1 \%$ of the fecal microbial counts, while only a slight increase $(7.9 \%$ to $16.6 \%$ ) was observed in the ineffective cases. In the effective cases, total straightchain SCFA increased, whereas they decreased in the ineffective cases (Table 8). Total branched-chain SCFA and putrefactive substances were decreased in both groups (Table 8 ).

\section{Effect of Long-Term Administration of FOS on the Intestinal Microflora}

The changes in the intestinal microflora over one year of administration of FOS are shown in Fig. 5 . In both chronic renal failure patients and healthy persons, the total counts were slightly increased after one month of FOS administration and remained at the same level through 12 months of administration. Enterobacteriaceae in the chronic renal failure patients tended to decrease gradually. The bacterial count of Bifidobacterium in the chronic renal failure patients increased from 
(A)

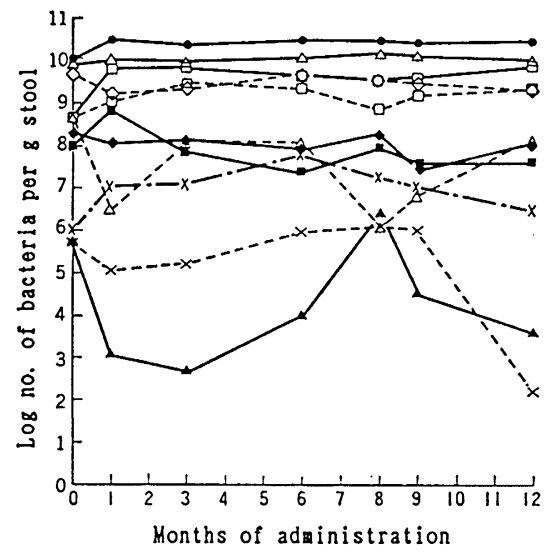

(B)

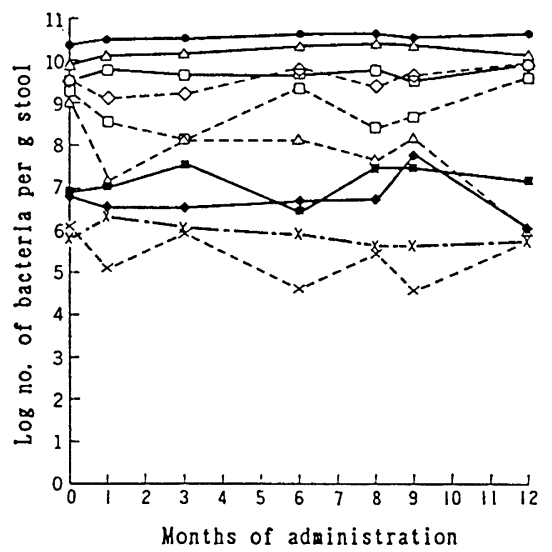

Fig. 5. Effect of long-term FOS administration on the intestinal microflora in chronic renal failure patients (A) and healthy persons (B). - - - Total counts; - $\square-$, Bifidobacterium; - - , Lactobacillus; $-\diamond-$, Eubacterium; $-\triangle-$, Bacteroidaceae; - - ,

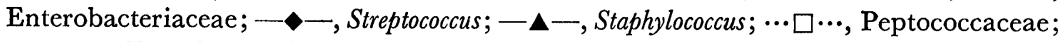
---- ×-.-, Clostridium perfringens; --- $\triangle---$, Clostridium-others.

(A)

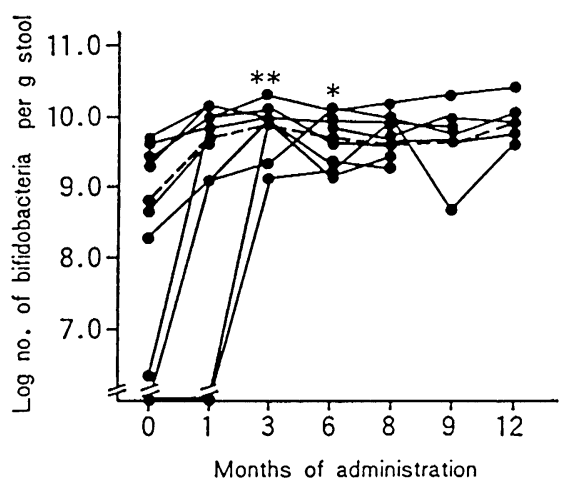

(B)

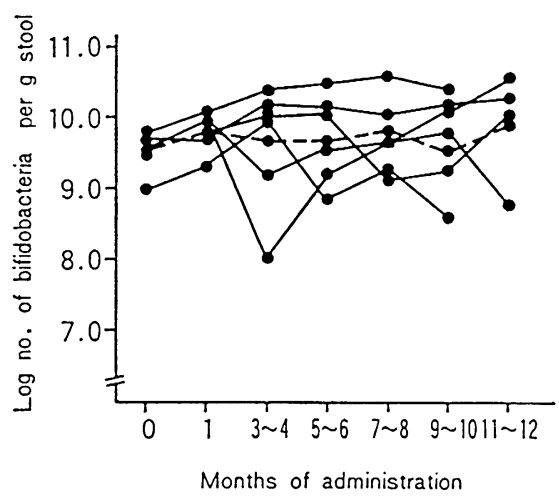

Fig. 6. Effect of long-term FOS administration on fecal bifidobacteria in chronic renal failure patients (A) and healthy persons (B). $\bullet-.-\bullet$ : mean count. Significant difference of the mean count from initial count: $*, P<0.05 ; * *, P<0.01$.

$10^{8.7} / \mathrm{g}$ stool $(2.5 \%)$ to $10^{9.8}(22.7 \%)$ in one month and fluctuated between $10^{9.6}$ and $10^{10.0}(11.6 \%$ and $26.8 \%$ ) thereafter (Fig. 6). In the healthy persons, the Bifidobacterium count was slightly increased by the ingestion of FOS (Fig. 6), while no changes were detected in the other intestinal bacteria (Fig. 5). Three chronic renal failure patients had no detectable Bifidobacterium before the study. The data on the changes in their intestinal microflora are graphically depicted in Fig. 7 . In two subjects, an abnormal flora caused by administration of antimicrobial agents before this study was normalized after 3 months of intake of FOS (Fig. 7 (B) and (C)). 

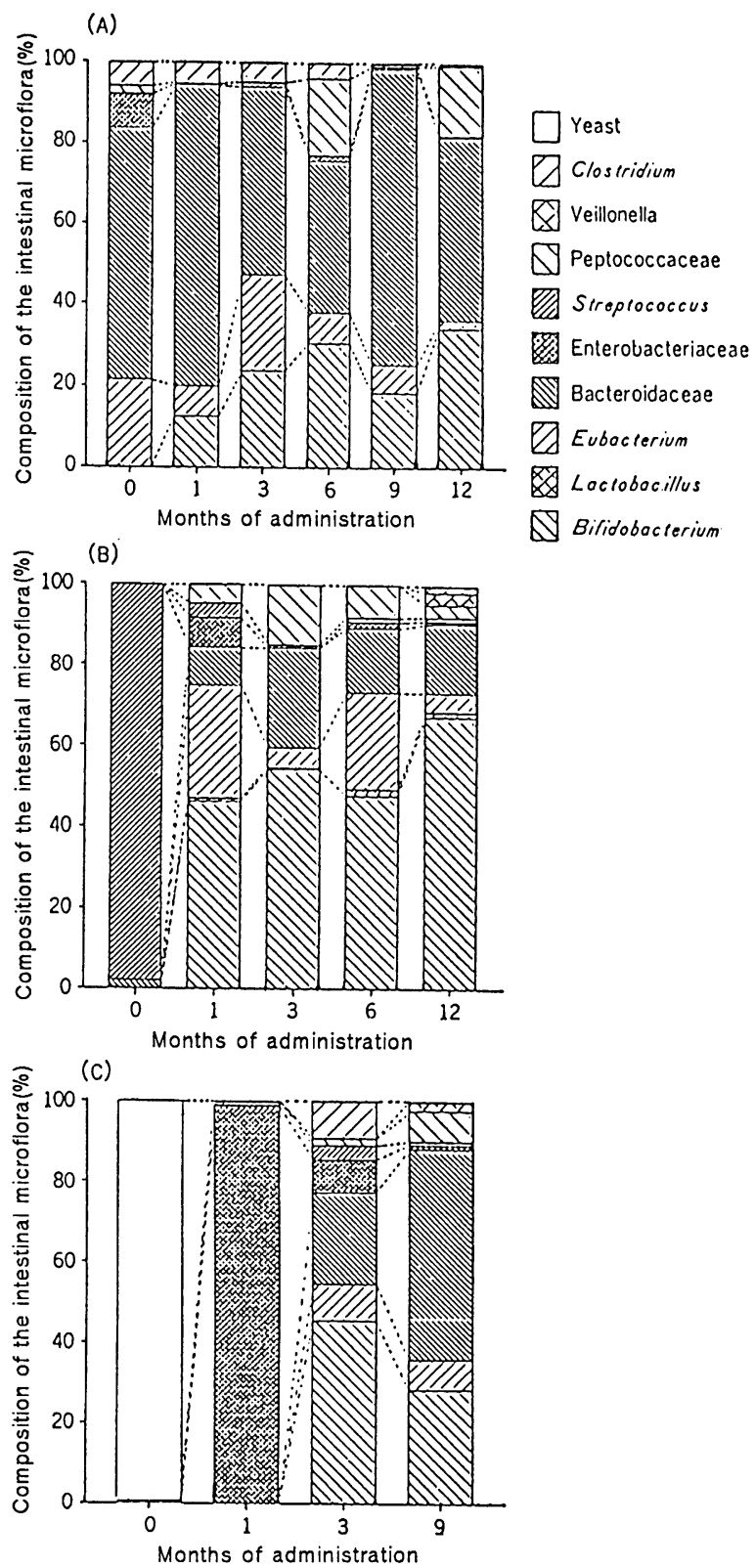

Fig. 7. Changes in the intestinal microflora of three chronic renal failure patients who had an abnormal microflora before the study. FOS was administered for one year. 


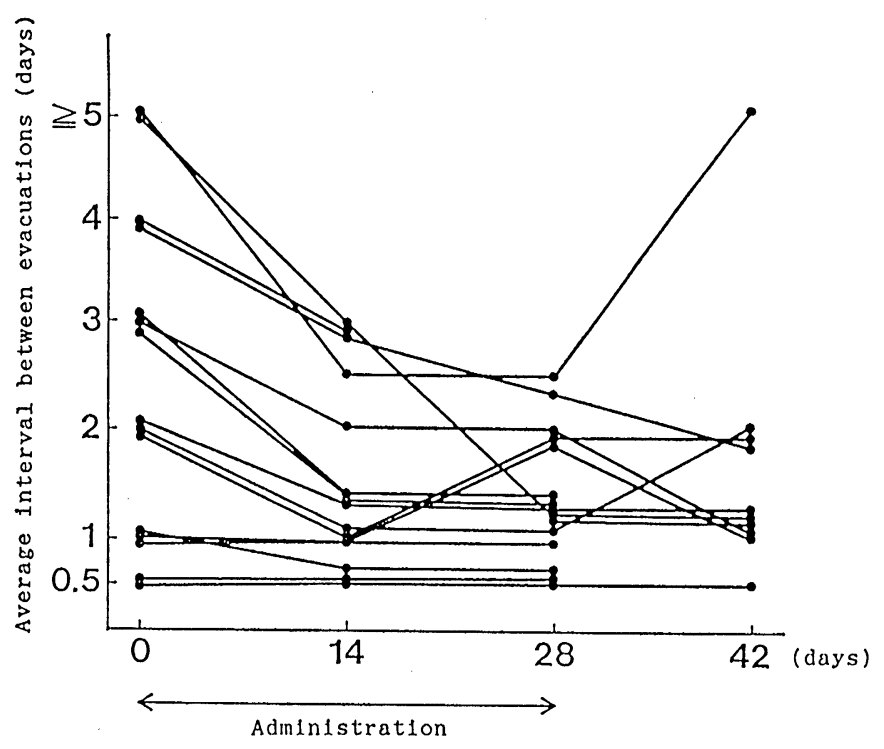

Fig. 8. Effect of FOS ingestion on constipation.

\section{Effect of FOS on Constipation}

The initial frequency of evacuation by the subject ranged from twice a day to once in 10 days. After ingestion of FOS, 11 subjects (73\%) were improved in terms of constipation, and all the subjects could defecate more than once in 3 days, as shown in Fig. 8 (9). In 2 subjects, the frequency of evacuation decreased again after discontinuation of FOS. No side effects occurred except for slight flatulence in 6 subjects.

\section{DISCUSSION}

This study demonstrated that daily intake of FOS lowered the total serum cholesterol. Moreover, HDL-cholesterol was kept constant, while apoprotein B was decreased in the effective cases by FOS ingestion, indicating the reduction of total cholesterol was mainly due to the reduction in LDL-cholesterol contents. Yamashita et al (16) also suggested that cholesterol reduction by FOS in diabetic patients was due to the reduction in LDL-cholesterol. The significantly low initial value for apoprotein B in the effective cases suggests that FOS may be effective in hypercholesterolemic patients having LDL-cholesterol lacking in apoprotein B. The reason for the increase in apoprotein $\mathrm{E}$ in the effective cases is not clear, but it may be that absorbed FOS metabolites by the intestinal microflora affected hepatic function, because apoprotein $\mathrm{E}$ is synthesized in the liver.

Chen et al (2) reported that a propionate-supplemented diet reduced the serum cholesterol. Ide et al ( 8 ) suggested that shorter chain fatty acids tended to decrease 
the HMG-CoA reductase activity, which is the rate-limiting step of cholesterol synthesis in animal tissues. In our study, straight-chain SCFA increased in the effective cases. Hosoya et al (7) indicated that about $20 \%$ of FOS was converted into propionic acid in anaerobic incubation with human feces. These data suggest that the cholesterol reduction by FOS is related to the metabolized SCFA. On the other hand, branched-chain SCFA and the putrefactive substances were decreased by FOS ingestion in both the effective and ineffective case. MacFarlane et al (10) pointed out that the branched-chain SCFA are useful indicators of the extent of bacterial proteolysis and subsequent deamination. It is reasonable that these branched-chain SCFA and the putrefactive substances were co-decreased by the administration of FOS, because the putrefactive substances are also derived from amino acids. Mallett et al (11) reported that the decrease in cecal branched-chain SCFA was associated with the reduction in cecal cancer-related enzyme activities in rats fed a low-digestible starch diet. Such changes may be due to the suppression of putrefactive intestinal bacteria and are desirable in preventing colon cancer.

We demonstrated that long-term administration of FOS caused no undesirable changes in the microflora. Furthermore, bifidobacteria appeared after 3 months of FOS administration even in the chronic renal failure patients who had an abnormal microflora in the colon due to administration of antimicrobial agents before the study. In the healthy persons, no marked increase in bifidobacteria was found because of the relatively high initial count of bifidobacteria. FOS may play a role in maintaining a high count of bifidobacteria.

The present study showed that FOS had a beneficial effect on constipation. It is considered that the alleviation of constipation by nondigestible saccharides is due to the high osmotic pressure of SCFA produced by saccharolytic intestinal bacteria and consequently peristaltic movement is accelerated. Our results might be explained by such a mechanism.

In conclusion, our clinical studies have demonstrated several useful characteristics of FOS, such as cholesterol reduction, suppression of putrefaction, normalization of microbial disorders in the colon and alleviation of constipation. It seems that the usefulness is related to the proliferation of bifidobacteria and other saccharolytic intestinal bacteria and also SCFA produced by these organisms. Additional research is needed to confirm these findings.

Acknowledgments. We thank Dr. Y. Hata of the Department of Medicine and Gerontology, School of Medicine, Kyorin University, Dr. T. Teramoto of the First Department of Internal Medicine, Faculty of Medicine, The University of Tokyo, Dr. Y. Takahashi of Department of Urology, Kitasato University Hospital, and Dr. S. Kameoka of The Institute of Gastroenterology, Tokyo Women's Medical College for cooperation with these clinical studies.

\section{REFERENCES}

(1) Benno, Y., K. Endo, T. Mizutani, Y. Namba, T. Komori, and T. Mitsuoka. 1989. Comparison of fecal microflora of elderly persons in rural and urban areas of Japan. Appl. Environ. Microbiol. 55: 1100-1105.

(2) Chen, W.J.L., J.W. Anderson, and D. Jennings. 1984. Propionate may mediate the hypo- 
cholesterolemic effects of certain soluble plant fibers in cholesterol-fed rats. Proc. Soc. Exp. Biol. Med. 175: 215-218.

(3) Finegold, S.M., V.L. Sutter, and G.E. Mathisen. 1983. Normal indigenous intestinal flora, p. 3-31. In D.J. Hentges (ed.), Human intestinal microflora in health and disease, Academic Press, New York.

(4) Hata, Y., T. Hara, T. Oikawa, M. Yamamoto, N. Hirose, T. Nagashima, N. Torihama, K. Nakajima, A. Watabe, and M. Yamashita. 1983. The effect of fructooligosaccharides (Neosugar) on hyperlipidemia. Geriatr. Med. 21: 156-167 (in Japanese).

(5) Hidaka, H., T. Eida, T. Takizawa, T. Tokunaga, and Y. Tashiro. 1986. Effects of fructooligosaccharides on intestinal flora and human health. Bifidobacteria Microflora 5: 37-50.

(6) Hidaka, H., M. Hirayama, and N. Sumi. 1988. A fructooligosaccharide-producing enzyme from Aspergillus niger ATCC 20611. Agric. Biol. Chem. 52: 1181-1187.

(7) Hosoya, N., B. Dhorranintra, and H. Hidaka. 1988. Utilization of [U $\left.{ }^{14} \mathrm{C}\right]$ fructooligosaccharides in man as energy resources. J. Clin. Biochem. Nutr. 5: 67-74.

(8) Ide, T., H. Okamatsu, and M. Sugano. 1978. Regulation by dietary fats of 3-hydroxy-3-methylglutaryl-coenzyme A reductase in rat liver. J. Nutr. 108: 601-612.

(9) Kameoka, S., H. Nogata, H. Yoshitoshi, and K. Hamano. 1986. Clinical study of fructooligosaccharide on chronic constipation. Jpn. J. Clin. Nutr. 68: 823-829 (in Japanese).

(10) MacFarlane, G.T., J.H. Cummings, and C. Allison. 1986. Protein degradation by human large intestinal bacteria. J. Gen. Microbiol. 132: 1647-1656.

(11) Mallett, A.K., C.A. Bearne, P.J. Young, and I.R. Rowland. 1988. Influences of starches of low digestibility on the rat caecal microflora. Br. J. Nutr. 60: 597-604.

(12) Mancini, G., A.O. Carbonara, and J.F. Heremans. 1965. Immunochemical quantitation of antigens by single radial immunodiffusion. Int. J. Immunochem. 2: 235-254.

(13) Mitsuoka, T., H. Hidaka, and T. Eida. 1987. Effect of fructo-oligosaccharides on intestinal microflora. Die Nahrung 31 : 427-436.

(14) Oku, T., T. Tokunaga, and N. Hosoya. 1984. Nondigestibility of new sweetener, "Neosugar," in rat. J. Nutr. 114: 1574-1581.

(15) Tokunaga, T., T. Oku, and N. Hosoya. 1989. Utilization and excretion of a new sweetener, fructooligosaccharide (Neosugar), in rats. J. Nutr. 119: 553-559.

(16) Yamashita, K., K. Kawai, and M. Itakura. 1984. Effects of fructo-oligosaccharides on blood glucose and serum lipids in diabetic subjects. Nutr. Res. 4: 961-966.

(17) Yoshioka, M., M. Hasegawa, H. Makimura, S. Takashima, K. Kitada, K. Ishii, and A. Matsuoka. 1984. Effect of fructooligosaccharides on blood glucose and pancreatic hormones. Diabetes 27: 814 (in Japanese). 